\title{
Investigating the Significance of the Communicative Approach in Teaching Grammar and Language Learning Activities-A Case Study of General English Students at Red Sea University
}

\author{
Nahid Alamin Ibrahim \\ Languages Department, Port Sudan Ahlia College, Port Sudan, Sudan
}

Email address:

nahidibrahim7272@gmail.com

\section{To cite this article:}

Nahid Alamin Ibrahim. Investigating the Significance of the Communicative Approach in Teaching Grammar and Language Learning Activities "A Case Study of General English Students at Red Sea University". Communication and Linguistics Studies.

Vol. 4, No. 3, 2018, pp. 72-79. doi: 10.11648/j.cls.20180403.12

Received: April 29, 2018; Accepted: June 21, 2018; Published: September 19, 2018

\begin{abstract}
The present study aims at investigating the effectiveness of the communicative approach on teaching grammar and language activities. The sample of the study consists of 193 (male and female students) of general English language at Read Sea University, Faculty of Arts and Humanities for the academic year 2012/2013. It is a mixed method research design "mixing both methods", using descriptive and interpretive analysis. A descriptive-correlation design was employed among the samples of the study to find out the effectiveness of communicative approach in teaching grammar and language activities, a student's pre-test and post- test and teachers' questionnaire were used for data collection. The data was analyzed by using a variety of statistical methods. The analysis of the data has focused on verifying the effectiveness of the communicative approach in understanding grammar and language activities compared to traditional approaches. The results of the investigation have revealed the following: a. Using the communicative approach in second language teaching is more effective in understanding grammar and language activities than traditional approaches. b. The Communicative approach is more sufficient in learning than other approaches. The study concluded with some recommendations.1. Language lab is important in order to provide learners with opportunities to be exposed to the target language as used by native speakers. 2. It is useful for EFL teachers to follow training courses in applying CA principles as other countries 3. Finally, further researches which are related to the communicative approach are suggested.
\end{abstract}

Keywords: Communicative Approach, Red Sea, Language Activities, Teaching Grammar

\section{Introduction}

It is obvious that, the words communication and communicative have tended to crop up with increasing frequency. And it follows that there has been a shift in emphasis in recent years from teaching language forms to teaching language functions. Many teachers and writers nowadays feel that, this is not enough but the whole methods of communication should be practice, which will in turn change the shape of the classroom lesson.

Brumfit [2] says that "the question for the teacher is: how close can my teaching bake pupils to their anticipated language needs in the outside world?... how much opportunity am giving members of any class to talk as individuals to each other, using as much English as they can say things which are as far as possible in response to what has been said before practice for fluency rather than accuracy.

Therefore, it could be said that if communicative teaching, is teaching language for a purpose, then the sense of needs to play a prominent part in the process of presentation and practice. Instead, of teaching forms with their meanings Going on to practice their uses, the teacher might begin with the use and proceed to teach examples of the forms that are required. This type of procedure would be communicative presentation and practice [2].

This study is trying to make a clear distinction between the 
words approach, technique and method. When the word approach is used it means that an idea or theory is being applied: that whatever the teacher does, certain theoretical principles are always born in mind. When a technique, is mention it means a procedure used in the classroom. Finally, a method is a set of procedures or a collection of techniques used in a systematically which it is hoped to result in efficient learning.

A technique then, is the narrowest term, meaning one single procedure. Methods consist of a number of techniques probably arranged in a specific order. The word approach is much more general and has the implication that whatever method or technique the teacher uses, that does not feel bound by these, but only by the theory in which others believe.

Communicative approach has to do with face validity of the materials and syllabus on which it is based. It is also un like traditional methods in practicing grammar activities inside classrooms it is fond that students like to practice in group-work or pair work rather than repeating a teacher's model.. Many researchers have been done in the application of the communicative approach to SL instruction [6]. The outcome of all these studies has proved that, the communicative approach with its meaningful interaction and critical thinking to SL instruction has been the most effective approach that enables Language learners practicing some function within a social context, not just accumulating knowledge of vocabulary and sentence level structures. (cited: from a research about investigating the effectiveness of the communicative approach and traditional approaches in word order and reading comprehension by Mohammed Elfaki, [14].

By interacting with their teachers and fellow pair work or group work students can receive practice in activating this known as class activities which are often characterized by information gap.

\section{Aims and Objectives of the Study}

The study aims at discussing and analyzing the process of communicative approach in teaching grammar and language activities and showing its implications on the classroom. The research attempts to shed light on effective communication as it has two important implications on teachers;

a) In recently years there are many exciting developments in language teaching. Many of which challenge our traditional views of what should happen in the classroom. Therefore, the study aims at showing how the new ideas of (communicative approach) can actually be applied in the classroom.

b) Another aim of the study is to answer the question of 'how to teach communicative ability. And this may lead us to the syllabus design level to specify and organize our teaching content in a systematic way.

c) One of the objectives of this study is that:

d) First, teachers thoroughly must understand the content and when their understanding is incomplete or uncertain, they need to spend more time studying and preparing. Teachers who fully understand the content when they teach use clear language and present more coherent explanations than those with weak

background.

Second, teachers of a second language must literally listen to themselves talk as they teach, monitor their own communication to try to be as clear and concise as possible. Seeing themselves on video tapes can be eye opening." Other processes such as peer coaching in which a colleague observes a portion of a lesson and provides feedback can be very helpful [3].

\section{Method}

This chapter presents the methodology of the research in order to investigate the hypothesis of this study propose that: the communicative approach is more effective in acquiring grammar and language activities more than the traditional approaches. This means that the communicative approach can lead learners not only to produce sentences accurately in a lesson but also use them appropriately when they are communicating outside of the classroom than the traditional approach. So, the communicative approach has been used to be compare with the traditional approaches in this investigation. To answer the research questions and prove the hypothesis of the present study, both the statistic and interpretive analysis have been used to elicit the required data.

This chapter discusses the research design, data collection instruments, testing the validity and reliability of the questionnaire which was distributed to university English language teachers, in different states of Sudan and both tests pre and post testes were given to the general English language students, at Red sea university. Data collection procedures, methods and procedures of data analysis, ethical considerations and concludes with a summary of the chapter.

\subsection{Data Collection}

\subsubsection{Subjects}

The subjects of the present study were the general English language students enrolled at Red Sea university, Faculty of Arts and Humanities who studied English as a university requirement. They were (193) Sudanese students (males and females). The students were divided randomly into two equal groups (experimental group and control group). All of them were undergraduates who were a mixture. (40) were males and (153) were females. They were almost equal in their ages. All the subjects had been taught English at seven years or more (in basic and secondary levels), and their mother tongue is Arabic.

Another subject of the study is 26 English language teachers from different Sudanese universities who were given a questionnaire to show their different opinions about English Language methods.

\subsubsection{Sampling Techniques (Learners)}

The sample of the present study included learners of General English language from Red Sea university in Red Sea State Faculty of Arts and Humanities. The sampling 
method that was used for the selection of learners was simple random sampling. Random sampling as defined by Kothari [7], refers to the method of sample selection which gives each possible sample combination an equal probability of being picked up and each item in the entire population to have an equal chance of being included in the sample

\subsection{Data Collection Instruments}

The data in this study was collected by utilizing two instruments for the study: two tests (pre and post) tests which were given to the general English language students, Read Sea university, Faculty of Arts and Humanities, and a questionnaire which was filled by English language teachers.

\subsubsection{The Students' Test}

The experimental and control groups were pre-tested on, grammar, and language activities. The grammar test consist of 14 items which involve different questions about some grammar series texts " support the view of many experienced teachers that grammar is based on communicative approach are not mutually exclusive. but rather mutually supportive, even in the same class the same lesson" Betty Schrampfer. The subjects were required to answer questions on i.e. information questions, parallel verbs transitive vs. intransitive verbs, change the active sentences to passive sentences, Tag question Information questions, Comparisons, Modal auxiliaries Countable vs. Uncountable nouns. Adjective clauses Tenses and Choice questions (Who) questions. Yes, and No, questions. All subjects in the experimental and control groups were tested to determine the post treatment of grammar and language activities the same test was given to the subject at the end of the semester as posttest.

The second instrument is questionnaire which consist of 32 items, filled by26 English language teachers to show their opinions about English language teaching methods, classroom strategies, teachers' and students 'interaction.

\subsubsection{Collection of the Data of Teachers' Questionnaire}

The questionnaire was selected as a tool for collecting data from teachers, because this tool has the advantage of providing greater anonymity, and hence, ensure the quality of information. The questionnaire was distributed among (26) English language teachers in different states in Sudan

\subsubsection{The Content of the Questionnaire}

The communicative approach applied, in teaching grammar and Language activities, teachers' interaction in the Class room, learners' Interaction in the classroom, teachers' responded to statement (1) Communicative approach often meets the learner needs (2) Communicative approach is not just limited to oral skills; reading and writing skills need to be developed to promote student's confidence in all four skills.

\subsubsection{Scale 1: The Communicative Approach Applied, in Teaching Grammar and Language Activities}

The questionnaire is composed of three scales of statements with (32) questions. The purpose behind constructing those questions was to obtain information which relates to the communicative approach. The scale is from Gardner [5], with some modifications e.g. Communicative approach is much more pupils oriented because it is pupils need. changed to be. Communicative approach often meets the learner needs. Also communicative approach seeks to personalize and co-vocalize language and adapted to immigrate interest students. Changed to Communicative approach headed for personalize and co-vocalize language and modified to interest students. The scale consists of five statements. It was intended to provide information about, communicative approach and how it improve the students' performance. The in formations were asked to mark whether, they Strongly Agree, Agree, disagree (e, strongly disagree or having no opinion with the statement

\section{(i) Scale 11 Teachers' Interaction in the Class Room}

This part of the questionnaire consists of ten statements (616) they are mainly about the Teachers' Interaction in the Class room. This scale also informed us about The Use of the target language as a normal medium for class room management and instruction reflects natural language acquisition

\section{(ii) Scale 111 Learners' Interaction in the Classroom}

This scale consists of (17-32) statement, it is intended to provide information about, Language analysis and grammar explanation may help some learners to some extent. This part from the questionnaire was named as motivation but it is changed to be, learners' interaction in the classroom. The whole statements were 30 . Two items were added therefore, there should be 32 statements in total

\section{(iii) Data Analysis (The Questionnaire)}

Data analysis began with estimating the instrument's reliability. Seliger and Shohamy, [11] states that "The criterion of reliability provides information on whether the data collection procedure is consistent and accurate". The equation of Cronbach's Alpha and Spearman Brown were applied to measure the reliability of Teachers' questionnaire. The results shown in the following table:

\section{(v) Sampling Techniques (Teachers)}

The sample of the present study included teachers of English language from different states of Sudan

\subsection{Procedure}

In this section, the results of the pre-tests and the post-tests will be statistically treated using the SPSS program. The tests will be as follows:

(1) Descriptive statistics to show the mean, the mode, the median and the standard deviation for each test in both groups (the control group and the experiment group)

(2) Paired sample T-tests for each group.

(3) Independent samples T-tests

(4) Effect size for the experiment group

To address the hypothesis of the study, two kinds of 
teaching approaches were applied to the subject. The experimental group was taught through the communicative approach, grammar and language activities (the name of the book is Fundamentals of English Grammar (third Edition -by Betty Schrampfer Azar [1]. Whereas the control group was taught through the traditional approaches, two language structures instructions which are grammar and language activities were selected as the target of instruction to test the hypothesis of the study. Both of the experimental and control groups were given the test. The experimental group consist of 97 students and they receive communicative instruction on the grammar and language activities which is based broadly on applying the theoretical perspective of the communicative language by making communicative competence the goal of language teaching and by acknowledging the interdependence of language and communication. The control group consist s of 96 students and they received traditional approaches instructions on grammar i.e. instructions: some words can be used both as noun and as a verb. If the word in italics is used as a noun draw a circle round the letter $n$ please. If the word in italics is used as a verb draw a circle round the letter $\mathrm{v}$, the lectures for each group, was held in three hours, the duration of the lectures took about three months.

\subsection{Methods of Data Analysis}

The researcher used statistical methods that are suits with the nature of the study, sample size and variables.

Reliability and validity are related to the measurement of any test which is supposed to measure reliable and valid data. Therefore, the reliability and validity the two tests in the present study have been measured as shown I $n$ the following section

Reliability of atest means that the test should yield the same scores if it is given to the same students in the same conditions in the near future. In otherwords, reliability concerns the consistency of the test judgments and results [4]
According to Hatch and Lazaraton [12] there are several

1/ Correlation of parallel or comparaple tests (for equivalence in form).

2/ Interrelate reliability check (for equivalence in judgment).

3/ Internal consistency (for consistency within atest)

4/ Correlation between test and re-test (for consistency over time)

The two tests in this study were administered to 193 general English students at the RedSea university, Faculty of Arts and Hummanties, at the beginig of the semester in the year 2012-2013. After 3 month at the end of the term it was admistered again (post-test) for the same group in the same conditions. The purpose of the (pre-test /post-test) is to assess the reliablility of the two tests ie. The application of the communicative aproach and traditional methods on teaching (Grammar and language activities). To measure the equivalence between the experimental group and the control group, the. T-test, for the two independent samples was used.

Table 1. Paired Samples Correlations.

\begin{tabular}{llll}
\hline & N & Correlation & Sig. \\
\hline Pair 1 pre\& post & 193 & .668 & .000 \\
\hline
\end{tabular}

Table 1 above shows that there is a high correlation between the two tests before the application of the new method (communicative approach and after the application on teaching Grammar and language activities).

Correlations: It is 0668: That means: there is medium correlation between this sample, before and after experience. In addition to that the direction of this correlation is negative after experience. The results of the statistical analysis of the grammar and language activities indicate that: the two tests are reliable i.e. they can be copied with similar results, Davies [4], maintains that reliability of T-test must have at least a correlation of 0.9 which gives a consistency of about 0.90 .

\subsection{Descriptive Statistics}

Table 2. The results of independent Samples-test for Equality of means between Experimental Group and control Group The application of communicative approach on teaching grammar and language activities.

Descriptive Statistics

\begin{tabular}{|c|c|c|c|c|c|c|c|}
\hline & $\mathbf{N}$ & Range & Minimum & Maximum & Mean & Std. Deviation & Variance \\
\hline pre & 193 & 57 & 29 & 86 & 57.51 & 11.834 & 140.053 \\
\hline post & 193 & 63 & 31 & 94 & 63.80 & 13.494 & 182.076 \\
\hline $\begin{array}{l}\text { Valid N } \\
\text { (listwise) }\end{array}$ & 193 & & & & & & \\
\hline
\end{tabular}

Paired Samples Statistics

\begin{tabular}{llllll}
\hline & & Mean & N & Std. Deviation & Variance \\
\hline Pair & pre & 57.51 & 193 & 11.834 & .852 \\
1 & post & 63.80 & 193 & 13.494 & .971 \\
\hline
\end{tabular}

Sample (1) pre (before experience): Size 193 range 57, minimum degree is 29, maximum degree is 86 and variance is 140 , 053

Sample 2. post (after experience) size:193 the same size for students, range 63, the minimum degree increase to 31 and the maximum degree 94 the mean of regards is 63.80 , standard deviation is 13,494 the variance 1 s 182 
Table 3. indicates That, there is strong significant differences $=-8.3885 i g=-000 \mathrm{Between}$ the sample, before and after the experience.

\begin{tabular}{|c|c|c|c|c|c|c|c|c|}
\hline & \multicolumn{5}{|c|}{ Paired Differences } & \multirow{3}{*}{$\mathbf{t}$} & \multirow{3}{*}{ df } & \multirow{3}{*}{ Ig. (2-tailed) } \\
\hline & \multirow{2}{*}{ Mean } & \multirow{2}{*}{ Td. Deviatio } & \multirow{2}{*}{$\begin{array}{l}\text { Std. Error } \\
\text { Mean } \\
\end{array}$} & \multicolumn{2}{|c|}{ 95\% Confidence Interval of the Difference } & & & \\
\hline & & & & Lower & Upper & & & \\
\hline Pair 1 pre-po & -6.295 & 10.427 & .751 & -7.776 & -4.815 & -8.388 & 192 & .000 \\
\hline
\end{tabular}

Validity: refers to the extent to which the data collection procedure measures what it intends to measure [11]. Validity means truth of the test it relation to what it is intended to examine. The test in this study is to be valid if it measures what it is supposed to measure, and is free from systematic errors. According to Davies[4]. Validity is often examined under the titles: face, content, construct, predictive and concurrent. Face validity has to do with the appeal of the test to the outcome judgment Red sea university and the university of Gezira have been asked to determine the face validity of the two tests. Their corrections have given more validity to the test. Content validity is to see whether the items of the test accurately present the thing being measured or not. Content validity is a matter of expert judgment [12]. Also, the instructors at Red Sea university and university of Gezira agree that the two tests have content validity.

Predictive and concurrent validity are closely related to each other, predictive validity is concerned with the objectivity of the test and to what extent that the test predicts some future outcome. On the other hand, concurrent. Validity is a matter of measurement, which notes its correlation with some other measures. therefore, the two tests items i.e.; pre and post tests have been taken from Fundamentals of English Grammar (third Edition -by Betty Shrimper (authentic materials) the outcome of this research prove that the two testes used in this study are valid, because they measure what they are supposed to measure.

\subsection{Reliability and Validity of the Questionnaire}

Reliability and validity are mainly related to the assessment of any questionnaire which is supposed to yield valid and reliable data. therefore, the reliability and validity of the questionnaire in the present study have been measured as shown below:

\subsection{Reliability}

Reliability of a questionnaire concerns the consistency of the questionnaire judgment and results [4]. To determine the reliability, the questionnaire in this study was shown to instructors at different Sudanese university; Khartoum university Dep. of linguistics, at kassla university in eastern Sudan. Dep. of English at Red Sea university faculty of Arts and Humanities Dep. of English and University of Gezira.

To find out whether the questionnaire measures the English language teachers' opinions about the English language teaching methods or not. Their ideas have added more reliability to the questionnaire. According to Hatch and lazaraton [5]. The reliability coefficient is always reported as a correlation (r)) in several statistical measurements such as, T-test, person correlation, ANOVA, and reliability analysis.
In this study the person correlation and the equation below have been used to find reliability

$$
\mathrm{R}=2 \mathrm{r} \div 1+\mathrm{r}
$$

When; $\mathrm{R}$ is Ret

$\mathrm{R}$ is correlation

$$
\begin{aligned}
\mathrm{R} & =\frac{2(0-67}{1+(0.67)}=\frac{1-34}{1-67}=0080 \\
& =\frac{\text { Validity }}{\text { Val }}=\frac{\sqrt{R}}{\sqrt{1-43}}=\frac{0.90}{1-67}
\end{aligned}
$$

Table 4. Correlation, Reliability and Validity of the Questionnaire.

\begin{tabular}{lllll}
\hline No & Sample study & Correlation & Reliability & Validity \\
\hline 1 & Teachers & 0.67 & 0.80 & 0.99 \\
\hline
\end{tabular}

\subsection{Reliability}

Krnbach Alpha: is a measure or indicator of the reliability and validity testing referred to Krnbach Alpha as a measure of consistency (internal consistency), and the value of Krnbach Alpha represents the minimum stability-resolution means that Krnbach Alpha scale and reservation for the stability of the scale was implemented for each form and all questions about the study and the value of the stability equation Average correlation coefficients between elements) elements of the test or questionnaire) and the following calculation formula (Cronbach's alpha coefficient standard) describes as below:

$$
\alpha=\frac{N \bar{r}}{1+(N-1) \bar{r}}
$$

Table 5. Reliability Statistics.

\begin{tabular}{ll}
\hline Cronbach's Alpha & N of Items \\
\hline 0.762 & 32 \\
\hline
\end{tabular}

The above table 6 shows that reliability coefficient for answers is the sample $(0.76 \%)$. The truth is the square root of the ratio suggesting that a questionnaire study is characterized by a degree of stability through which the purpose of the study is supposed to yield reliable data.

Validity concerns the truth of the questionnaire and its relation to what is intended to measure. The questionnaire in this study will be valid if it measures what is supposed to measure. Davies [4] says that "Validity is often discussed under the headings: face, construct, content, predictive and concurrent" Face validity concerns the appeal of the questionnaire to the lay out judgment. In this respect, the researcher asked instructors of English language at different Sudanese universities to determine 


$$
\text { Validity }=\sqrt{\text { Reliability }}=\sqrt{\mathrm{R}} a
$$

We measure the validity of questionnaire by applying the formula.

\subsection{Expert-Validation (Face Validity)}

Accompanied with a proposal included the aims and objectives, statement of the research problem, questions, hypotheses and variables of the study, the researcher administered the communicative approach and traditional approaches in teaching grammar and language. Activities designed by the researcher (2012) reviewed by assistant professors in English language at University of Khartoum in Faculty of Arts (department of linguistics), university of Gezira and kassla university. To ensure the validity of content and to check it. The experts were asked to check every item in the light of the objectives and the variables of the research. They suggested that (3) items out of the (35) should be reduced, separated, deleted and changed by another. At last, the opinions of all reviewers indicated the suitability of the scale Then the researcher did all the required modifications of the scale.

\section{Discussion and Results}

The main purpose of this chapter is to present, analyze and discuss the data which was collected by the instruments of the study, specifically the students pre and posttests in addition to English language teachers' questionnaire. Moreover, the study uses both types of data analysis: descriptive and interpretive analysis of the communicative ' and traditional approaches to SL instructions, mainly in the Teaching of grammar and reading comprehension. The data which was collected from the subjects was presented in tables of percentages for each scale in this study. This chapter has been divided into two sections. Section one is concerned with the analysis of general information of a questionnaire related to the respondents (teachers) in different universities in Sudan. They were presented in tables and percentage for each information and scale in the study. Section two is concerned with the data collected from the subjects by using the pre -test and post -test in the study, has been analyzed statistically by a T-test.

\subsection{Analysis of the Data: Some Statistical Criteria}

In total and out of 30 questionnaires distributed to the teachers there were only 26 questionnaires recovered. Out of the four lost questionnaires two were discarded for having incomplete personal data. Analysis and results of teachers' questionnaire were presented and discussed in this section in order to find out the answers of the study questions and to test the study hypotheses. The results were sustained with tables and graphs. The Data collected have been processed by using the statistical packagefor social science (SPSS) program.

There are two methods of analysis used; descriptive and interpretive analysis.

\subsection{Teachers' Responded to the Questionnaire}

This section presents the data obtained from the questionnaire which the teachers completed. The following is a Chi-square analyzes to examine the relevant data and details are as follows:

Table 6. Teachers' responded to statement (1) Communicative approach often meets the learner needs.

\begin{tabular}{lll}
\hline Frequency & Percent & Valid Percent \\
\hline 1 & 3.8 & 3.8 \\
1 & 3.8 & 3.8 \\
6 & 23.1 & 23.1 \\
18 & 69.2 & 69.2 \\
26 & 100.0 & 100.0 \\
\hline
\end{tabular}

$69 \%$ strongly agree, $23 \%$ agree, $0 \%$ no opinion, $3.8 \%$ disagree, $3.5 \%$ strongly disagree.

The results in the preceding (table 6) indicate that $69 \%$ of the responses strongly agree, $23 \%$ agree with the statement which said: Communicative approach often meets the learner needs. The sum of agreement is $91 \%$, whereas $3.8 \%$ disagree, $0 \%$ had no opinion and $3.5 \%$ strongly disagree. meaning that the communicative approach depends on the process of communication for mastering the language.(i

Table 7. Statement 2: Communicative approach is not just limited to oral skills; reading, writing skills need to be developed to promote student's confidence in all four skills.

\begin{tabular}{lll}
\hline Frequency & Percent & Valid Percent \\
\hline 1 & 3.8 & 3.8 \\
8 & 30.8 & 30.8 \\
17 & 65.4 & 65.4 \\
26 & 100.0 & 100.0 \\
\hline
\end{tabular}

$65 \%$ strongly agree, $30 \%$ agree, $0 \%$ no opinion, $2.7 \%$ disagree, $3.8 \%$ strongly disagree

Table 7 shows that:

In responded to statement (2) The general rate of agreement is $95 \%$ from the total number of the teachers. This means that, the majority of the English language teachers agree with the idea that: Communicative approach is not just limited to oral skills; reading, writing skills need to be developed to promote student's confidence in all four skills. $0 \%$ from the teachers who participated in the questionnaire had no opinion $2.7 \%$ disagree while $3.8 \%$ strongly disagree.

\subsection{Testing the Hypotheses of the Study}

The first Hypothesis is That: The communicative approach is more effective in teaching grammar and. language activities than the traditional approaches

To test the hypotheses of this study the researcher used the items in (Scale A, B and C1) in the questionnaire, items from (1-5), are about communicative approach and the importance of including the communicative tasks, in each lesson the goal of many English language teachers today, so that they can 
prepare their students to communicate in English. the rate of agreement in question 2 is very high it is $95 \%$ also question 5 is $92 \%$ which indicates that there is a high degree of agreement about both items. So it becomes clear that, communication is required that students perform certain functions as well, such as statement 2 in the questionnaire " Communicative approach is not just limited to oral skills; reading, writing skills need to be developed to promote pupils confidence in all four skills "being able to communicate requires more than mastering linguistic competence. Hymes [6], The theoretical core of which is Hymens' communicative competence theory knowing when and how to say what to whom and the theory of Halliday's functional linguistics communicative language teaching Item from (6-16) examine the teachers' interaction in the classroom $91 \%$ of the teachers who agree that, communication with an individual student in a large class means that trying to communicate with students on personal level will make a great frustration and disturbance We find that the communicative approach emphasis on students ' initiative and interaction rather than traditional approaches. Also the rate of agreement is $89 \%$ of the responses agree with the idea that Classrooms should provide opportunities to run through real life situation and provide opportunities for real communication, Emphasis on creative role plays simulations /surveys /projects /play test-all produce spontaneity and improvisation not just repetition and drills as for the direct method, grammatical method. The study found that, the majority of the teachers respondents are agree of the idea that communicative approach can promote meaningful interactions discussion of relevant issues and critical thinking skills, so communicative approach is more effective in acquiring grammar and language activities, than the traditional approaches.

The second hypothesis of this study is that: Students will become more active after the experiment and promote their scores in the post test

It is said that, one of the basic assumptions of CLT is that, by learning to communicate students will be more motivated to study a foreign language, since they will feel they are learning to do something useful with the language, also it is said that it will be more useful if the teachers give opportunities for the students to express their individuality by having them share their ideas and opinions on a regular basis. Item 7 in the questionnaire shows that the general rate of agreement is $87 \%$ of the total number of the responses who see that: Classroom activities maximize opportunities for learners to use target language in a communicative way for learning full activities, helps to make minds more flexible and spire self-confidence, to help learners to develop their second language and should aim to provide support from the teachers.

So students will become more active by the many opportunities for cooperative interactions with their fellow students and teachers thus they will promote their scores. In conclusion and with reference to the hypothesis of the research (1 and 2) it can be said that, most of the English language teachers agree with the idea that, the communicative approach with its meaning full interaction, and critical thinking is more effective in acquiring grammar and language activities than traditional approaches.

\section{Conclusion and Recommendations}

\subsection{Conclusion}

This study was conducted to find answers to the main objectives of the research questions and test the hypotheses attached to them.

The main objective of this study is to prove that the communicative approach to SL instruction is more effective in acquiring Grammar and language activities than traditional approaches. Which means that the study is an attempt to display the application of the communicative approach in teaching grammar and language activities in learning L2. Such as games conversation practice role play information gap ...etc. To attain this objective, the researcher has tried to incorporate all the research procedures, principles and the literature that is relevant to prove the hypotheses of the study, the intention was given to the effectiveness of the communicative approach to $\mathrm{S}$. L instruction in acquiring S. L Grammar and language activity in comparison to traditional approaches. Therefore, the traditional approaches have been used as a comparative variable in this study

The second question of this study was "Does the communicative approach improve the understanding of grammar and language activities and it is more appropriately than traditional approaches"?

\subsection{Recommendations}

Based on the findings of this study, the following recommendations can be considered useful in teaching English Language:

1-Add more authentic texts in Sudanese universities

2-Recent methodological developments should be taken into consideration by EFL teachers.

3-EFL teachers should receive training from other countries in applying CA principles.

4- Language lab is an important in order to provide learners with opportunities to be exposed to the target language as used by native speakers.

5- Students should work in pairs and groups to promote their speaking skills.

6-Teachers should select" texts" that are related to the students' needs.

7- Textbooks should be based on the communicative interactions, to help the students in oral communication.

8 -Teachers have to be more flexible in classroom methodology.

As a result of the limitation of the study, the research may have neglected or ignored some points that can be relevant to the CLT approach in foreign language learning. So, further studies could investigate the areas related to applied linguistics. Among the significant affective factors that 
affecting foreign language learning and need more researches concerning other skills especially Reading skill and listening skill. More researches should be undertaken in learning English as a foreign language such as oral communication and willingness to communicate. More researches are also needed in other factors affecting foreign language learning such as cognitive factors (aptitude, intelligence, memory, learner's belief). The role of curricula designers in promoting and altering curricula to suit the needs of learners would be a useful subject of study. All these suggested kinds of studies hoped to contribute to better in acquiring and mastering L2.

\section{References}

[1] Azar Schrampfer Betty (1941) printed in the united states of America.

[2] Brumfit, C. (1984) Communicative methodology in Language Teaching Cambridge: Cambridge University Press.

[3] Clickman (1990) The research manual Design and statistics for applied linguistics, published by Heninle \& Heninie pule.

[4] Davies Alan, (1990), Principles of language testing. Oxford, UK; Cambridge, Mass., USA: B. Blackwell, 1990.
[5] Hatch, Evelyn. (1983) Psycholinguistics: A Second Language Perspective. Rowley, Mass: New Bury House.

[6] Hymes, Dell. (1971) Competence and performance in linguistics theory; in R. H uxky and E. Ingram (eds) Language acquisition: Models and methods. London: Academic Press.

[7] Kothari (2006:60) Research Methodology methods and techniques. new Age international publishers $4^{\text {th }}$ edition.

[8] Larsen- Freeman, D (2001) ' Individual cognitive/affective learner contributions and differential success in SLA in M. P.

[9] Leaver, B. L et al (2005:43) Leaver, B. L et al (2005) states that (p.43). Northam (2010).

[10] Richards, J, \& Rodgers Th. (2006) Approaches and methods in Language teaching. New York: Cambridge University press.

[11] Seliger and Shohamy (1989:185) Second language Research Methods. Oxford University press

[12] VogtW Paul, (2014), Quantities and qualities research, Guilford Publications.

[13] Wilkins, D, A. (1978). National syllabus. London: Oxford University press

[14] Mohammed Elfaki (2014), The Communicative approach in language teaching; A critical perspective. 